\title{
"¿Dónde Quedó el Árbol de las Placentas?" Tansformaciones en el Saber acerca del Embarazo/Parto/Puerperio de dos Generaciones de Triquis Migrantes a la Ciudad de México.
}

\author{
"What Happened to the Placentas Tree?" \\ Transformations in the Knowledge about \\ Pregnancy/Labor/Puerperium in two Triqui Migrant \\ Generations to México City.
}

Zuanilda Mendoza González ${ }^{1}$

${ }^{1}$ Departamento de Historia y Filosofía de la Medicina,

Facultad de Medicina, Universidad Nacional Autónoma de México zuanilda@hotmail.com
RESUMEN La movilización constante y progresiva de numerosos grupos sociales del campo a la ciudad ha sido una de las variables demográficas más importantes en las últimas décadas. Sin embargo, al interior de este proceso de cambio no han sido considerados los aspectos de salud/enfermedad/atención, a los que nosotros reconocemos como centrales para ejemplificar y analizar el intenso proceso de transformación sociocultural que sufren estos grupos. Para el caso de este artículo nos interesa resaltar los cambios que se presentan en los saberes acerca de su proceso reproductivo, ejemplificado a través del embarazo/parto/puerperio en dos generaciones diferentes de hombres y mujeres indígenas triquis migrantes del estado de Oaxaca a la ciudad de México. Nos acercaremos a su proceso reproductivo a partir de sus saberes, las redes de apoyo que les permiten solucionar o no un problema, los recursos procedentes de su medicina tradicional o de la biomedicina y la eficacia de los mismos.

PALABRAS CLAVE Reproducción; Embarazo; Aculturación; Migración; Conocimiento.

\begin{abstract}
The constant and progressive mobilization of numerous social groups from the country to the city has been one of the most important demographic characteristics of the last decades. Although health, disease, and health care have received little attention, we recognize these dimensions as central to exemplify and analyze the intensive process of sociocultural transformation that these groups suffer. In this article, we emphasize the changes that are present in knowledge about the reproductive process, exemplified during the pregnancy/labor/puerperium in two different generations of native Triqui men and women migrants from the state of Oaxaca to Mexico city. We explore the Triquis reproductive process through an understanding of their local knowledge, their problem solving networks, and their traditional medicine.
\end{abstract}

KEY WORDS Reproduction; Pregnancy; Acculturation; Migration; Knowledge. 


\section{INTRODUCCIÓN}

El proceso reproductivo ha sido prioritario, desde hace algunas décadas a la fecha, en los programas de atención y promoción de la salud desde la perspectiva médica institucional. Fue abordado a través de programas de salud reproductiva, materno/infantil y planificación familiar que tienen como objetivo centrar sus acciones en la mujer, identificada como responsable de la reproducción y excluyendo de este terreno la participación del varón al que se ubica en el ámbito de lo productivo $(1,2)$. Es decir: se definen y se construyen identidades genéricas diferenciales y desde esa perspectiva se mira la reproducción.

Se reduce el concepto de proceso reproductivo a fecundidad y gestación, localizándolo en el cuerpo femenino y por lo tanto privilegiándolo como unidad de análisis, a pesar de ser las parejas las que se reproducen. Conceptualizar la reproducción exclusivamente en el ámbito biológico femenino, ha fomentando la utilización de modelos de análisis estadísticos que tratan de explicar y predecir comportamientos futuros de poblaciones, con la intención de incidir sobre ellos, y se pierde a través de esta visión la complejidad del proceso reproductivo $(3,4,5)$. El análisis de la fecundidad bajo esta perspectiva ha tendido a manejar casi de manera obligada a la anticoncepción, interpretada como acciones de control y reducción de esa fecundidad.

\section{PERSONAJES Y LUGARES}

Este artículo surge de una investigación más amplia que conforma mi tesis doctoral (a), donde planteo la necesidad de conocer las constantes y modificaciones que se dan en los saberes acerca del proceso reproductivo en un grupo de migrantes indígenas a la Ciudad de México. Es importante señalar que la migración es uno de los fenómenos sociales más intensos en el desarrollo demográfico de México, siendo la población indígena una de las más activas en este proceso. Han sido innumerables y diversos los enfoques desde donde se estudia el fenómeno migratorio, pero muy reducida la información respecto de las condiciones de salud/enfermedad de estos grupos sociales, de sus saberes o del proceso de discontinuidad/continuidad cultural de estos grupos socioculturales como resultado de su migración. Fue nuestra intención incursionar en la descripción y análisis de su proceso reproductivo para hacer evidente un complejo proceso de transformación cultural producto de una constante e intensa interacción social con mayor diversidad de actores sociales en la urbe, a la par del mantenimiento de formas de comprender $y$ atender la enfermedad propias de su bagaje cultural indígena.

Me limitaré a ejemplificar dicho proceso de continuidad/discontinuidad cultural a través de la descripción y análisis de los saberes de mujeres y varones de dos generaciones de migrantes respecto del embarazo/parto/puerperio.

Los actores sociales son integrantes de grupos domésticos triquis del estado de Oaxaca, migrantes a la Ciudad de México, residentes en la ciudad desde hace aproximadamente 10 a 15 años y que como consecuencia de su reterritorialización mantienen una relación frecuente $y$ directa con diferentes actores sociales y representantes de diversas instituciones que ejecutan programas específicos de atención con ellos, al mismo tiempo que establecen un vínculo de continuidad con su región.

La voz que nos interesa escuchar es la de mujeres y varones triquis migrantes de la primera y segunda generación, su experiencia acerca de este aspecto del proceso reproductivo, los apoyos que reciben al interior de su grupo doméstico y la interacción que establecen con actores sociales externos a él. Lo que nuestro trabajo pretende constatar es que para las nuevas generaciones existe un abanico más amplio de opciones; dicho abanico es producto de una compleja madeja de cambios que podrían catalogarse tanto económicos como culturales, que dependen de su situación familiar y de su ubicación con respecto a redes de apoyo más amplias, así como de condiciones macroestructurales (6).

Las mujeres son Agustina y Paty. Agustina tiene cuarenta y tres años de edad, es originaria de Copala, Oaxaca (región de origen), es analfabeta, está casada con Justo hace veinticuatro años. Tienen ocho hijos; el mayor, de veintitrés años, casado con dos hijos, es migrante desde hace dos años en EE.UU.; de los hijos pequeños, tres viven en Copala con su abuela paterna y su nuera, los otros cuatro viven con ellos en la ciudad. 
Paty tiene diecisiete años de edad, está casada con Felipe desde hace dos años, tienen un hijo de un año y medio de edad. Ella nació en Copala, pero a los dos o tres años de edad migra con su familia a la Ciudad de México. Estudió hasta sexto año de primaria, es bilingüe en español y triqui, y se dedica a atender una pequeña tienda que tiene en su cuarto y a la venta ambulante de artesanías.

Los varones son Justo y Felipe. Justo tiene cuarenta y cinco años, es originario de Copala. Analfabeto, está casado con Agustina desde hace veinticuatro años y tienen ocho hijos. Ha desempeñado diversas actividades productivas: campesino en su pueblo, en los campos de algodón y jitomate en San Quintín y Ensenada o albañil en la Ciudad de México. Ahora vive en la ciudad desde hace seis meses.

Felipe tiene veintiún años de edad. Es originario de Copala, está casado con Paty desde hace dos años y tienen un hijo. Migró a la ciudad a la edad de diez años, cursó hasta tercer año de primaria en Copala, pero abandonó la escuela al migrar con su familia a Culiacán y Ensenada. Viven en La Merced desde hace seis o siete años, y ahora comparte el cuarto con su tío Justo, hermano de su papá. Se ha dedicado a diversas actividades laborales, entre ellas la albañilería en su pueblo y en la ciudad, la elaboración y venta de artesanías en varias ciudades, y como jornalero en el cultivo de jitomate, algodón y uva en el norte del país.

\section{EL EMBARAZO, PARTO Y PUERPERIO: UN PROCESO EN CONSTRUCCIÓN DIFERENCIAL POR GENERACIONES Y GÉNERO.}

En este apartado describiré las características del proceso reproductivo entre los miembros de las dos generaciones de este grupo doméstico, buscando las diferencias en sus historias reproductivas y sus saberes acerca del embarazo/parto/puerperio.

Ambas parejas inician su vida reproductiva a temprana edad, en el caso de las mujeres más que los varones: Agustina alrededor de los trece años y Paty a los quince; Justo a los veinte años y Felipe a los diecinueve.

\section{EL EMBARAZO}

Ellos reconocen que las mujeres se embarazan porque tienen relaciones sexuales con sus esposos, "al juntarse la sangre de la menstruación con el semen del varón se formará el nene". Por ello el momento ideal para lograr la gestación es la menstruación. Comparten las representaciones acerca de la gestación, pero utilizan términos diferentes para nombrarlos: mientras para Agustina y Justo es la "sangre de la mujer y el agua del varón" los que forman al niño, para Paty y Felipe es el óvulo y el espermatozoide, uno contenido en la sangre menstrual y el otro en el semen que, al unirse, forman al nuevo niño. Esta información la obtuvieron de la escuela y la integran a los saberes de su grupo.

El embarazo fue vivido por ambas parejas como un proceso natural, si bien vigilado con mayor o menor regularidad por la partera en el pueblo o en el predio de La Merced, agregándose el cuidado médico prenatal en el caso de Paty. No se lo considera un proceso enfermante o anormal por lo que desarrollaron su vida cotidiana sin modificaciones. Son el esposo y las mujeres de la familia -suegra, mamá o hermanas-, quienes vigilan que la embarazada cumpla con las normas que su grupo establece.

Agustina cursó sus embarazos en el pueblo acompañada de su suegra y esposo. Ellos facilitaron y vigilaron que durante sus embarazos se alimentara bien, lo cual significa ingerir todos los días tortilla, frijol y salsa, así como comer a sus horas para evitar el riesgo de un aborto. Otro cuidado señalado era evitar trabajos pesados, aunque esto, en realidad, se limitaba a la prohibición de lavar cobijas en el río, no comer cosas frías y bañarse en el temazcal.

En cambio Paty, que cursó su embarazo en la ciudad, comió con regularidad frutas, verduras, leche o yoghurt, carne una o dos veces por semana, tortillas y huevo diariamente. Felipe se preocupaba constantemente de que comiera "cosas buenas", para que el "nene" creciera y estuviera fuerte. Las madres de Paty y Felipe cuidaron de evitarle el trabajo pesado; incluso no le permitían cargar cubetas de agua, lavar ropa gruesa (pantalones, toallas, cobijas), caminar rápido, o correr; todos estos cuidados eran para evitar un aborto. El apoyo recibido de su esposo 
es ampliamente valorado por ella, considera que fue muy cuidadoso y considerado en contraste con otros varones del predio que no ayudan a sus esposas.

La mujer también debe tener cuidado de no adoptar posiciones inadecuadas porque el niño se acomodará mal en su vientre y esto le traerá por consecuencia un mal parto.

Respecto a la prohibición de comer cosas frías o tocar agua, eran indicaciones dadas a Paty por su mamá, pero ella las cuestionaba: "Mi mamá y mi suegra me decían que no comiera yo cosas frías porque me podía dar dolor o podía tirar al nene. Pero yo comí aguacate, duraznos, refrescos fríos, hasta bolis (congeladas) y nunca me pasó nada, pero a mi mamá le decía que ya no lo iba a hacer".

Otro aspecto muy vigilado por la primera generación y puesto en duda por la segunda es la satisfacción de los antojos. Se considera que no satisfacer un antojo durante el embarazo será la causa de una marca en el cuerpo del recién nacido. Esto tiene por consecuencia que la familia y el esposo de la embarazada vigilen con insistencia que la embarazada satisfaga todos sus antojos.

Agustina nos refiere que su suegra constantemente le compraba en el mercado de Copala fruta o dulces que a ella se le antojaban. Ella fue la principal vigilante de este proceso, apoyada por su hijo. Su suegra le satisfacía hasta lo que no se le antojaba, por si las dudas.

En el caso de Paty, son su mamá y Felipe quienes estuvieron al tanto de lo que ella quisiera comer para satisfacerla. Paty acepta esta interpretación, aunque no entiende por qué razón sucede.

Con relación a la movilidad fetal, ambas parejas concuerdan en afirmar que dependiendo del género del nene será el inicio de la movilidad fetal, la constancia y fuerza de ésta. Los varones se mueven más temprano y con más fuerza, en cambio las mujeres son más tardías en su movilidad y lo hacen con menos fuerza.

Lograr el primer embarazo lo antes posible es una necesidad identificada y compartida por ambas generaciones, el retraso pondrá en duda la capacidad reproductiva de la mujer y en consecuencia le puede traer reclamos y maltrato por parte de su esposo. Se identifican recursos a los cuales acceder cuando una mujer no puede lograr fácilmente un embarazo: el más utilizado por todos los grupos domésticos es una planta medicinal que se trae del pueblo. Cuando las mujeres la toman y se bañan en el temazcal o con agua caliente lograrán fácilmente un embarazo.

La sintomatología que se reconoce en el curso del embarazo es escasa, el estado nauseoso que se presenta en ocasiones, se asocia con aumento de calor en el estómago de la embarazada, que se resuelve con la ingesta de té de plantas frescas.

El diagnóstico del embarazo lo realizaron de forma similar: por la ausencia de la menstruación y por la consulta a una partera, quien confirmó el embarazo. No obstante, Paty y Felipe también consideraron necesario acudir al centro de salud, para que la doctora lo confirmara.

La noticia del primer embarazo fue recibida con gran alegría por parte de los esposos, principalmente en caso del primer embarazo, incluso festejando con la familia a través de la ingesta de alcohol: "Él se puso muy contento, nada más hablaba de eso, de que ya íbamos a tener su hijo, eso era muy importante y muy bueno para él."

Existió una diferencia respecto del cuidado del embarazo por los diferentes curadores. En el caso de Agustina, ella realizó el control en forma constante y regular con la partera mientras estuvo en el pueblo, su suegra y su esposo procuraban que cada semana o cada quince días la partera llegara a revisarla, la limpiara con tabaco y aguardiente, quemara copal y le pasara el huevo y la vela para que todo saliera bien. En los casos en que los embarazos transcurrieron durante sus migraciones, el control con la partera fue muy esporádico, en una o dos ocasiones, porque no podía contar con el recurso. Con relación al control médico prenatal, en sus primeros embarazos no lo tuvo. En los últimos, por estar en la ciudad, sí acudió al centro de salud en una o dos ocasiones para que la doctora revisara al "nene", porque le gustaba que le pongan los aparatos que ella usa y así estaba más segura de que todo funcionara bien.

Paty, en cambio, mantuvo un control constante de su embarazo con la doctora del centro de salud. Desde que supo de su embarazo, cada mes o cada quince días acudía al centro de salud por indicación de Felipe y por convicción 
propia. Para ella era muy importante que la doctora la revisara con regularidad para confirmarle la edad del niño, que estuviera bien y que no fueran a presentarse complicaciones durante el parto. No se realizó exámenes más especializados porque la doctora no se los indicó, pero sí le hubiera gustado hacerse un ultrasonido, "dicen que con ese examen se ve bien el nene, nosotros sí queríamos verlo así". Lo que nunca aceptó fue tomar medicamentos ni ponerse vacunas: los consideraba riesgosos, "pueden hacer que los nenes nazcan chuecos o malhechos". Durante tres o cuatro ocasiones en su embarazo fue revisada por la partera del predio. Ella la sobaba, la manteaba para acomodarle al "nene", la soplaba y limpiaba para evitar que malos aires fueran a ocasionar problemas en el nacimiento.

Ninguna de estas dos parejas suspendió su actividad sexual durante sus gestaciones; no existe una indicación precisa de abstinencia en esta etapa. Agustina ni siquiera se cuestionó si era adecuado o no, ella seguía estando con Justo porque él así se lo demandaba y a ella no le molestaba, ni se sentía enferma. Paty en cambio lo dudó, aunque su mamá y su suegra le decían que mientras no tuviera dolor o sangrado, ella podía seguir con su esposo. Ella decidió, apoyada por Felipe, preguntarle a la doctora su opinión. "Un día fui porque Felipe me mandó a preguntarle, ella me dijo que sí podíamos tener relaciones, pero que él se pusiera el condón, yo no sé porque me dijo así, ha de ser porque si no se puede uno volver a embarazar y nacer gemelos".

El principal temor que se tiene durante el curso del embarazo es la presencia de un aborto: ellos le Ilaman "tirar al nene". Está ocasionado por el frío o los aires; por esta razón una mujer embarazada debe tener mucho cuidado, tendrá que recibir baños y té muy caliente para evitar la pérdida, sólo el calor contrarrestará el aborto. Esta situación se da principalmente en mujeres a las que se les reconoce débiles o frágiles. Ellas deben de ser cuidadas desde sus menstruaciones y al casarse porque de lo contrario serán estériles y nunca lograrán un embarazo. Para Paty la conformación física de la mujer es el principal factor que ocasiona un aborto; en cambio para Agustina la principal causa es la falta de cuidados contra el frío o bien las envidias y los aires que pueden ocasionar en la mujer la pérdida de sus embarazos. La causa de esterilidad siempre es adjudicada a la mujer; ella será la que tendrá que cuidarse o curarse el tiempo necesario hasta lograr un embarazo, en caso contrario será rechazada por el varón y devuelta con sus padres ya que "no sirve para darle familia a su esposo".

\section{EL PARTO}

Agustina ha tenido todos sus partos en su domicilio, ya sea en el pueblo, en el cuarto donde vivían al migrar al norte o en la Ciudad de México. Sólo en el primer parto fue necesario el auxilio de la partera; con los otros nueve ha sido su esposo quien le ayuda sujetándola de la cintura con sus manos o con el zoyate (cinturón tejido de tela y palma), le aprieta fuerte para abajo y con eso los nenes nacen, todos han nacido sin complicaciones aparentes. "A todos mis hijos los he tenido en mi casa. A mí me gusta así, en mi cuarto, me siento y mi esposo me ayuda y ya. Porque hace falta que le aprieten a uno la cintura para que el nene pueda nacer. Así va uno haciendo fuerza y cae el nene".

Para Agustina los dolores de parto no son fuertes, se le pasan rápido; al parecer sus trabajos de parto tuvieron una corta duración (un par de horas). Además reconoce que esos dolores son necesarios para que el niño nazca, sin ellos no podría nacer, "son para que el nene vaya cayendo". En cuanto los percibe más fuertes inician los deseos de pujar (ganas de ir al baño) y no tarda la expulsión. También reconoce que siempre antes del nacimiento del niño sale un líquido que acompaña al "nene", ella no sabe para que sirve pero siempre está ahí, en cuanto el dolor ya es muy fuerte se expulsa el líquido. Tampoco reconoce la función de la placenta, a la que ella Ilama "ombligo", sólo sabe que siempre hay que esperar a que salga, viene después del nacimiento y cuando no sale las mujeres van a morir del sangrado. A ella nunca le pasó eso, el "ombligo" siempre salió rápido, su esposo lo espera, lo recoge, lo envuelve en una bolsa y lo lleva a enterrar. Siempre lo han enterrado, aún cuando estaban en Culiacán o aquí en México. Su esposo iba a enterrar la placenta, porque si se tira, el "nene" puede enfermar. 
En cambio Paty, como el resto de las madres jóvenes en el predio urbano, tiene una amplia preferencia por el parto hospitalario. Para ella el lugar óptimo donde se debe tener un parto es el hospital, porque ahí están los doctores que son los que realmente saben atenderlos y evitar cualquier tipo de complicación que pudiera surgir en el curso del mismo. Ella tuvo su parto en el ámbito hospitalario. Durante las últimas semanas del embarazo acudió a la doctora del centro de salud para que le proporcionara la referencia necesaria al hospital. Ella le había comentado a Felipe los beneficios de atenderse en el hospital y él estaba de acuerdo en "no exponerse", aunque su mamá y su suegra no compartían esta opinión. Para ellas, como para el resto de las señoras mayores del predio, el lugar adecuado para tener un hijo es la casa de la parturienta. Las mujeres deben estar entre sus gentes, no tienen por qué acudir a gente extraña, sobre todo a médicos varones que no tienen por qué ver a las mujeres. Las mujeres deben ser fuertes para tener a sus hijos solas o ayudadas por sus familiares y parteras. Paty y Felipe no estaban de acuerdo con sus madres, para ellos las cosas no son iguales en la ciudad que en el pueblo, aquí y ahora no es necesario exponerse al riesgo de que algo se complique y la mujer o el niño mueran. Ellos dicen tener miedo de que algo pueda suceder y en el cuarto no tengan ningún recurso para poder solucionarlo, en cambio el hospital les proporciona la certeza de solución.

En cuanto inició el trabajo de parto, la mamá de Paty estuvo pendiente, le preparó té de una planta medicinal traída del pueblo, mandaron Ilamar a la partera para que revisara al "nene", la sahumó, la limpió y "sacó medida" (proceso adivinatorio para dar un pronóstico). Paty refiere que fueron muchas horas y los dolores, muy fuertes: "yo no sé porque serán así de fuertes esos dolores, pero siente uno que se va a partir". Su mamá tenía todo listo para que naciera el nene ahí, incluso le insistía en que se arrodillara y pujara, "yo tenía mucha vergüenza y mucho miedo, yo creo que por eso no nacía el nene. Entonces Felipe dijo que nos fuéramos al hospital".

La espera en el hospital también fue larga, en dos ocasiones la rechazaron y le indicaron caminar por varias horas, ella no quiso regresar a su casa: prefirió esperar ahí hasta que su hijo nació. El trato del personal de salud y las exploraciones ginecológicas fueron consideradas por ella como necesarias, le daba vergüenza, pero era necesario, incomprensible pero necesario, "yo no sé qué tocan los doctores cuando la revisan a uno, aunque duele mucho, pero así ellos ya saben que nene ya va a nacer".

Fueron varias horas de espera, cuatro o cinco exploraciones ginecológicas, frío, dolor y cansancio, pero una vez en el hospital ella consideró que todo iba a ser rápido y seguro. Se sometió sin preguntar y sin cuestionar a todas las órdenes que recibió de las enfermeras y los médicos, era necesario hacerlo así para que todo saliera con éxito. Le dolió y fue muy molesta la colocación de la anestesia, pero ella sabía que con eso iba a estar bien, la herida en el periné para ampliar el espacio de expulsión fue muy dolorosa, pero no se quejó porque eso era lo que los doctores tenían que hacer.

"La verdad es que sí da vergüenza que la tenga a uno así, porque a uno cuando la han vista así; pero yo digo que así debe de ser para que los doctores puedan hacer todo lo que necesitan, para que el nene nazca bien y no le pase nada".

Una vez nacido el "nene" le permitieron bañarse y bañarlo, lo dejaron con ella en su cama, les dieron de comer a los dos y le enseñaron la forma de darle de mamar. Esto es reconocido por Paty como aspectos positivos que no podría haber tenido en su casa, sobre todo el aseo y la alimentación. Para Paty resultaba desagradable pensar en estar sucia, Ilena de sangre y agua, después del nacimiento, y que no se le permitiera bañarse hasta que fuera al baño de vapor. Además, su hijo estaría en las mismas condiciones.

El hospital le proporcionó seguridad, confianza, disminuyó su dolor y le brindó el confort de una alimentación e higiene.

Con relación al manejo de la placenta desconocen lo que se hace con ella en el hospital, pero no le prestan ninguna importancia. Consideran que seguramente la desechan en la basura, ya que no tienen la necesidad ni el esmero de enterrarla. Pero para ellos no tiene importancia lo que se haga con ella, ya que consideran innecesario tener los cuidados que dicen su mamá y otras señoras del pueblo: enterrarla o 
colgarla en el árbol, para evitar que el "nene" se enferme o llore demasiado. Para Paty y Felipe esto no es cierto; aunque la placenta se tire, el "nene" no se enfermará; esto puede corroborarse con la gran cantidad de niños triquis del predio que han nacido en el hospital cuyas placentas no se cuidaron como en el pueblo y tampoco han enfermado ni han muerto, como afirmaran las mujeres mayores.

\section{EL PUERPERIO}

Éste es el período de mayores cuidados hacia la mujer: tanto Agustina como Paty permanecieron durante más de diez días recostadas sin realizar ningún tipo de actividad. Este período puede guardarse con cierta regularidad gracias al apoyo que ambas puérperas tuvieron de sus esposos, madres y/o suegras. Para la gran mayoría de la gente de la comunidad es importante que una mujer después de tener un parto, guarde reposo el mayor tiempo posible, la norma comunitaria hace referencia a veintiún días. Sólo así es posible evitar las complicaciones que pueden presentarse después del parto, y la mujer podrá recuperar la fuerza necesaria para trabajar, alimentar a su hijo y más adelante volver a embarazarse. De no guardar estos cuidados las consecuencias pueden ser la muerte de la madre o la infertilidad.

Agustina y Paty permanecieron acostadas en sus lechos, levantándose sólo para ir al baño o para acudir al baño de vapor, ya sea en el pueblo o en la ciudad. El grupo doméstico vigiló que no realizaran ninguna actividad y le proporcionaron la ayuda necesaria para resolver todas sus necesidades en la vida cotidiana. Se les abasteció de comida y ropa limpia, se cuidó a sus hijos y se los alimentó. Gran parte de estas funciones las cumplió el esposo, en caso de estar presente; en segundo lugar, la mamá y/o la suegra.

Entre los cuidados importantes está la vigilancia de evitar el frío -sobre todo en la alimentación-, y el contacto con agua o aires, también evitar que la mujer tenga dolores en su vientre o bien que la leche no fluya en cantidades necesarias para alimentar a sus hijos, así como la tardía complicación de esterilidad. Agustina procura durante este período sólo tomar atole, caldos, quelites, tortilla y chiles, para así no tener ningún tipo de complicación. Es su esposo quien se encarga de la preparación de los alimentos, el aseo de la casa y la ropa para evitar que ella toque el agua fría, aunque estos cuidados no duran mucho tiempo porque frecuentemente Justo está borracho y no hay quién atienda a los niños. Esto hace que Agustina se reincorpore tempranamente (nunca antes de siete días) a sus obligaciones domésticas. También es importante que la mujer permanezca fajada mientras dure el puerperio; se le coloca en la cintura el zoyate bien apretado, para evitar que se le suba la matriz y la ahogue. Esta es causa de muerte reconocida por Agustina y Justo en este período, por eso ella permaneció durante más de cuarenta días fajada y evitando levantar cosas pesadas.

Un aspecto central es el baño que las mujeres puérperas deben recibir con la mayor regularidad. Mientras permaneció en el pueblo, Agustina se bañó cada tres días en el baño de temazcal, pero en los casos en que sus partos fueron fuera del pueblo, sustituyó el baño de temazcal por baños de vapor o de agua caliente, tanto en sus migraciones al norte del país como en la Ciudad de México. Sin embargo, ella considera que haber recibido en algunas ocasiones el baño de temazcal le ayudó a que sus partos fueran rápidos, con poco dolor y sin complicaciones. Considera que los baños con agua caliente le ayudan a recuperarse, pero no les da el mismo valor que al temazcal.

Una vez terminado el baño, ya sea en el pueblo o fuera de él, siempre han realizado la fiesta de la terminación del baño. Para Agustina y Justo es indispensable Ilevarla a cabo para agradecer la sobrevivencia del nene y propiciar hijos sanos, porque, cuando la fiesta no se realiza como debe ser, el dios del baño puede enojarse y hacer que esa pareja ya no tenga hijos. La fiesta la realizan de la misma forma en que se hace en el pueblo: con atole de panela o carne, se invita a familiares y compadres para que acompañen a los nuevos padres.

Para Paty el puerperio fue un período muy aburrido. Su mamá y su esposo permanecieron con ella como "guardianes", vigilando que realizara todas y cada una de las indicaciones necesarias. Dudaban que ella las realizara voluntariamente por considerarla muy niña y sobre todo rebelde. Prefirieron vigilarla constantemente 
y así evitar cualquier tipo de complicación. Permaneció en cama durante veinte días. Sólo se le permitía levantarse para comer, para alimentar a su hijo y para ir al baño. Permaneció fajada con el zoyate todo el tiempo que estuvo acostada para evitar que se le subiera la matriz (indicación de su mamá). Ella considera que la faja le servía para tener mayor fuerza, se sentía menos débil y podía enderezarse fácilmente, así como para propiciar el flujo de leche necesario para su hijo. "Mi mamá venía a revisarme el zoyate, que estuviera bien apretado, porque dice que se le sube a uno algo que tiene en la panza y eso hace que uno se enferme y se muera. Me regañaba bastante si no me lo apretaba, pero es que a mí me daba mucha comezón y por eso me lo aflojaba."

Su mamá y su esposo se encargaron de preparar los alimentos, lavar la ropa de ella y del niño, atender el negocio y mantener su cuarto limpio. Su mamá ponía especial atención en la alimentación porque era importante cuidar que durante este período no tomara nada frío; por eso le preparaba caldos de pollo, res o pescado, en ocasiones con chile para aumentar su calor, quelites, atoles y totopos, todos estos alimentos considerados calientes y favorecedores de la lactancia. No le permitían lavar ni tocar el agua fría porque esto también podría traer complicaciones como dolor y sangrado. No podía tomar refresco ni agua fresca, solamente té y atole. A los tres días de haber regresado a su casa la llevaron al baño de vapor. La acompañaron su mamá, sus hermanas mayores y Felipe; la bañaron con agua caliente y ahí mismo lavaron sus ropas. El baño se repitió cada tercer día hasta que cumplió los veintiún días de puerperio. Al terminar el baño su mamá le hizo el atole de frijol y de carne para realizar la fiesta del baño. Paty y Felipe no saben por qué se realiza esta fiesta, sólo reconocen que todas las mujeres del predio que han tenido su bebé y al terminar los días en que las Ilevan al baño de vapor, realizan un festejo en donde se toma este tipo de atole, se festeja con refresco y cerveza, se invita a familiares y vecinos. En su caso su mamá le hizo el atole, invitaron a su madrina, sus hermanos, familiares que viven en el predio y a la familia de Felipe que está en la ciudad. Se compraron rejas de refresco y cerveza, y festejaron hasta el otro día. Después de la fiesta ya la dejaron levantarse, cargar a su hijo, hacer de comer y lavar las cosas más pequeñas; las pesadas las siguió lavando su mamá durante unas semanas más.

Paty no recibió el baño de temazcal durante su puerperio, ya que no tienen temazcal en la ciudad. Pero cuando su hijo tenía ocho meses de nacido fueron al pueblo. Ahí su cuñada insistió en bañarla, porque no se había bañado como debía ser después del parto. Reconocen que el baño de temazcal es más provechoso para las mujeres recién paridas porque les permite recuperar su fuerza y tener su cuerpo macizo después del parto. Paty indica que no cuidarse como es necesario en el puerperio trae como consecuencia complicaciones posteriores en las mujeres, incluso considera que las mujeres de la ciudad tienen tantos "achaques" al Ilegar a cierta edad por no cuidarse detalladamente; padecerán de dolor de espalda y de cadera, hinchazón en las piernas y várices, todo a consecuencia de que entra mucha frialdad en su cuerpo, que les ocasiona enfermedad constante, incluso esta frialdad puede traer por consecuencia la imposibilidad de tener nuevamente hijos. "Por eso es que uno debe cuidarse y hacerle caso a su mamá o a su suegra, a quien la esté cuidando; si uno no se cuida después empiezan los problemas"

\section{CAMBIOS Y CONSTANTES EN LOS SABERES}

Podemos afirmar que los saberes respecto del proceso s/e/a en ambas generaciones muestran aspectos similares, tal es el caso de representaciones respecto del cuerpo en relación a la reproducción, los cuidados, la vigilancia y atención del proceso, cuyas explicaciones pasan principalmente por aspectos del saber popular como la polaridad frío/caliente, la necesidad del calor para la reproducción, la vigilancia de los aires, el cumplimiento de las normas y obligaciones con la comunidad y con lo sobrenatural. Este saber se encuentra más integrado y congruente entre representaciones y prácticas en el caso de la primera generación, en quien observamos explicaciones y mayor consistencia de su hacer. En cambio, en la segunda generación se muestran variaciones e inconsistencias entre representaciones y prácticas, que guardan 
relación con una socialización primaria o endoculturación en la ciudad y un grado mayor de escolaridad, que les ha permitido un contacto más frecuente con las instituciones y representantes de la biomedicina, evidente en la conformación de sus saberes.

Entre las etapas del proceso reproductivo también encontramos diferencias entre las generaciones y los géneros. En el embarazo los cuidados que siguen son mínimos pero existe una constante vigilancia de la partera que le permitirá a la embarazada llevar a buen término la gestación sin complicaciones hasta un parto normal. En la segunda generación se agrega la intervención del profesional médico en el control prenatal, incluso buscando mayor tecnología y especialización cuando se cuenta con los recursos económicos para pagar la atención privada. Pero en forma conjunta estas madres y sus familias cumplieron con los antojos, se protegieron del frío, accedieron a protegerse con limpias (a) y recurrieron a la adivinación para asegurar un proceso exitoso.

El parto es el período en donde la práctica médica alópata ha ganado espacios, quizá por ser el período más temido donde se reconoce el riesgo de muerte para la madre y el niño. Mujeres y varones de la segunda generación tienen una representación de la capacidad técnica de los profesionales de la salud como elemento de mayor certidumbre en la resolución del parto, asegurando así la sobrevivencia. No se pone en cuestionamiento una atención institucional, impersonal, fuera de su espacio cotidiano y sin la compañía familiar: en lo que centran su elección es en la capacidad técnica del profesional y en los recursos que puede utilizar para asegurar su eficacia.

Por último, el puerperio se presenta como un espacio familiar de recuperación, protección y apoyo para la mujer, casi sin vigilancia de los curadores médicos o curanderos. Espacio ritual con amplia participación de la red de apoyo que pasa por las mujeres de las familias de origen y por el apoyo del varón. Durante este período es donde observamos un cumplimiento más puntual y apegado a las representaciones populares, aunque modificadas para el caso de las jóvenes de la segunda generación que parieron en la ciudad.

En la relación que estos grupos sociales tienen con la biomedicina se muestra mejor accesibilidad y disponibilidad, con mayor número de instituciones, servicios privados, farmacias y recursos especializados en la ciudad. Pero sobre todo se observa una representación colectiva que se reproduce en todos los grupos acerca de la superioridad, eficacia y capacidad resolutiva de la medicina alopática a diferentes escalas y bajo diferentes condiciones. Es la presencia, disposición y acceso en términos económicos, culturales y sociales lo que hace que exista una penetración de esta práctica.

Acerca de su saber popular en el ámbito doméstico y el reconocimiento de sus curanderos encontramos diferencias entre ambas generaciones. En la primera generación hay un mayor dominio del saber popular, no sólo en términos del uso de los recursos sino un pleno conocimiento y confianza en él, aspecto que se está transformando en la segunda generación, en quien podemos considerar que se está creando dependencia de la atención médica. No obstante, los saberes y prácticas tradicionales están presentes y vigentes en ambos grupos domésticos.

Podríamos suponer que en futuras generaciones este saber vaya mermando al resultar menos funcional a las madres o ser menores los recursos terapéuticos propios a los que recurran estas familias. Sería importante en estudios subsecuentes identificar el número de curanderos reconocidos por estas poblaciones y el saber con qué cuentan las madres de las nuevas generaciones.

\section{ALGUNAS CONCLUSIONES}

Al identificar y caracterizar a los grupos en donde se generan estos procesos sociales se logra tener una comprensión y explicación de su proceso reproductivo. Al considerar las condiciones materiales de vida, el tipo de relaciones y redes sociales que establecen, las oportunidades diferenciales de acceso a los recursos para la salud y atención de la enfermedad, y sobre todo el bagaje cultural de cada grupo social -lo que les condiciona expectativas, decisiones y obstáculos respecto del cuerpo, su reproducción biológica y social-, corroboramos que es el estilo de vida de los sujetos lo que nos permite entender su proceso reproductivo en función de su pertenencia a un determinado grupo sociocultural (7).

De nuestros datos surge el proceso reproductivo como una categoría compleja que 
tiene que ver con representaciones y prácticas relacionadas con la participación en una vida sexual, desde el cortejo o construcción de la relación de pareja, el ejercicio de la sexualidad, la unión, la construcción de la familia, el significado de la maternidad y paternidad, el valor de los hijos, el ejercicio del poder de cada género, la experiencia de la reproducción y la crianza. Reconocemos a los actores sociales como el resultado de la interacción de una diversidad de factores individuales, sociales y culturales que condicionan sus deseos y posibilidad de decisión en cada uno de los sucesos de su vivir diario, incluida su reproducción. Debe señalarse que la conformación de dichas expectativas y decisiones se da de manera diferencial desde el género, la generación, el grupo cultural de pertenencia, el estrato social, el nivel de escolaridad formal, entre otras variables. Es decir que dichos deseos y decisiones están cruzados por condiciones materiales e ideológicas, lo que nos permite dar cuenta de la complejidad del proceso de reproducción $(8,9)$.

Es el proceso reproductivo un ejemplo valioso de la medicina de este grupo social que nos permite distinguir la diversidad de elementos que integran su sistema de conocimientos, significaciones y prácticas que inciden en su proceso salud/enfermedad/atención/muerte (s/a/e/m) en un momento histórico determinado. Sus diversas etapas además de tener un componente biológico común, idéntico en cualquier grupo humano, presentan otra dimensión fundamental de unicidad y diferenciación en sus formas de manifestarse por estar intrínsecamente relacionada con el conjunto sociocultural de procedencia, por lo que debemos considerarlo un proceso biocultural.

El estudio de los saberes sobre este proceso pone en evidencia no sólo las estrechas conexiones con otras temáticas centrales como la sexualidad, la fertilidad y la preservación del grupo, sino también la diversidad de formas que socialmente dan respuesta a los eventos mencionados. Esa respuesta social refiere a un lenguaje simbólico pero también al lenguaje médico/técnico expresado en un conjunto de saberes, maniobras o terapias que los actores ponen en juego ante cada suceso específico.

El fenómeno de coexistencia de conceptos, creencias y prácticas tradicionales y biomédicas respecto del embarazo, parto y puerperio, constituye un ejemplo de la síntesis en los saberes de los conjuntos sociales. Postular la existencia de un sistema mixto nos Ileva a aceptar la presencia de diferentes alternativas de atención, no siempre en integración armónica, así como pensar que todo proyecto o programa debe advertir la importancia de la diversidad.

Una perspectiva importante en la investigación sobre el proceso reproductivo son los estudios demográficos $(10,11,12)$, donde se pone énfasis en la fecundidad como el principal determinante del cambio demográfico registrado en México durante las últimas décadas. Los datos nacionales reportan que la tasa global de fecundidad descendió de casi siete hijos por mujer a principios de los años '70 a 3,3 en 1990; en la última década del siglo XX continuó disminuyendo a un ritmo más lento: en la actualidad (año 2000) se estima que se sitúa en alrededor de 2,4 hijos por mujer (11).

Es importante señalar que el descenso de la fecundidad iniciado desde mediados de la década del '70 no se ha producido de forma homogénea en todo el país ni en todos los grupos de población. La transición de la fecundidad en México, como en otros países, se presentó primero entre la población más urbanizada, la más escolarizada y, en general, la de mayores niveles de bienestar; después se difundió hasta otros grupos menos favorecidos, entre los cuales se encuentra la población indígena, cuyo comportamiento reproductivo es poco conocido debido a las reducidas fuentes oficiales de datos para su estudio, que hasta hace pocos años no diferenciaba la información por grupo étnico, así como el interés reciente por las explicaciones cualitativas para este fenómeno.

Resulta central para nosotros reconocer la enorme influencia de la condición migratoria sobre la fecundidad, que genera cambios en los patrones reproductivos de las parejas, condicionados por variables como las configuraciones culturales diversas, escolaridad, actividad productiva y tipo de unión conyugal, así como el papel esencial de la mujer migrante que se manifiesta en la realización de múltiples roles, y que tiene repercusiones en las relaciones conyugales e intergeneracionales de la familia (13). Estos cambios más sutiles, menos visibles y más difíciles de aprehender son rara vez tratados en la literatura sobre migración y sobre proceso reproductivo. 


\section{NOTAS FINALES}

a. "De la casa del nene al árbol de las placentas". Proceso reproductivo, saberes y transformación cultural entre los triquis de Copala en la Merced. Tesis doctoral. Programa Doctorado en Antropología Social, del Centro de Investigaciones en Estudios Superiores en Antropología Social, sede México, DF. Dirigida por el Dr. L. Eduardo Menéndez S. Disertación Pública en Agosto del 2004. b. Limpia: Procedimiento terapéutico realizado a través del barrido del cuerpo enfermo con un ramo de plantas medicinales, flores, huevo u otro elemento terapéutico, con el fin de eliminar aires, calor $u$ otras entidades que pueden causar o contribuir a la presencia de la enfermedad.

\section{REFERENCIAS BIBLIOGRÁFICAS}

1. Figueroa JG. Comportamiento reproductivo y salud: reflexiones a partir de la prestación de servicios. En: Careaga G, Figueroa JG, Mejía MC, compiladores. Etica y salud reproductiva. México: PUEG, PUIS, Miguel Angel Porrúa; 1991. p. 289-312.

2. Figueroa JG, Aguilar BM, Hita MG. Una aproximación al entorno de los derechos reproductivos a través de un enfoque de conflictos. Estudios Sociológicos. 1994;12(34):129-152.

3. Cervantes Carson A. México: políticas de población, derechos humanos y democratización de los espacios sociales. En: IV Conferencia Latinoamericana de Población. La transición demográfica en América Latina y el Caribe. México: INEGI-IISUNAM; 1993. vol II p. 759-789.

4. Cervantes Carson A. Políticas de población, control de la fecundidad, derechos reproductivos. Una propuesta analítica. En: García B, coordinadora. Mujer; género y población en México. México: El Colegio de México, Sociedad Mexicana de Demografía; 1993. p. 363-420.

5. Lerner S, Quesnel A. Instituciones y reproducción. Hacia una interpretación del papel de las instituciones en la regulación de la fecundidad en México. En: Alba F, Cabrera G, compiladores. La Población en el Desarrollo Contemporáneo de México. México: El Colegio de México; 1994. p. 85-117.

6. Ortega J, Hoil J, Lendechy A. Proceso reproductivo femenino: género, representaciones y actores sociales. Una reflexión desde el contexto yucateco. En: Tuñón PE, coordinador. Género y salud en el Sureste de México. México: ECOSUR, UNFPA, COESPO; 1999. vol 2 p. 423-443.
7. Menéndez EL. Estilo de vida, riesgos y construcción social. Conceptos similares y significados diferentes. Estudios Sociológicos. 1998;16 (46):37-67.

8. Lerner S, Quesnel A, Yañez M. La pluralidad de trayectorias reproductivas y las transacciones institucionales. Estudios Demográficos y Urbanos. 1994;9(27):543-578.

9. Elu MC, Leñero L. De carne y hueso, estudios sociales sobre género y reproducción. México: IMES; 1992.

10. Benítez Zenteno R. La transición demográfica en México. Problemas y consecuencias. En: La Universidad Nacional y los problemas nacionales. México: UNAM, Sociedad y cultura: 1979. vol 2 p. 43-89.

11. Consejo Nacional de Población. Veinticinco años de cambios en la migración interna de México. En: La situación demográfica de México. México: CONAPO; 1999. p. 63-73.

12. Consejo Nacional de Población. Cuadernos de Salud Reproductiva: Oaxaca. México: CONAPO; 2000.

13. Mummert G. Mujeres de migrantes y mujeres migrantes de Michoacán. Nuevos papeles para los que se quedan y para los que se van. En: Calvo T, López G, coordinadores. Movimientos de población en el occidente de México. Zamora: Colegio de Michoacán, CEMCA; 1988. p. 281-297. 


\section{BIBLIOGRAFÍA CONSULTADA}

Benítez Zenteno R. Visión Latinoamericana de la transición demográfica. Dinámica de la población y práctica política. En: IV Conferencia Latinoamericana de Población. La Transición Demográfica en América Latina y el Caribe. México: INEGI-ISUNAM; 1994. vol1 p. 29-53

Consejo Nacional de Población. Comportamiento reproductivo de la población indígena. México: CONAPO; 2001. (Serie Documentos Técnicos)

Elu MC, Lager A. Maternidad sin riesgos en México. México: SSA, PUEG, IMES, FNUAP. The population Council; 1994.

Figueroa JG. Derechos reproductivos y el espacio de las instituciones de salud: algunos apuntes sobre la experiencia mexicana. En: Ortiz Ortega A, editor. Proyecto de investigación y acción sobre derechos reproductivos [Documento metodológico]. México: Secretaría de Salud; 1993. p. 1-17.

Figueroa JG, et al. Experiencia reproductiva y patrones reproductivos en México. En: Stern C, coordinador. El papel del trabajo materno en la salud infantil. Contribuciones al debate desde las ciencias sociales. México: The Population Council, El Colegio de México: 1996. p. 109-138.

Figueroa JG. La presencia de los varones en los procesos reproductivos: algunas reflexiones. En: Lerner S, editora. Varones, Sexualidad y Reproducción. Diversas perspectivas teóricas, metodológicas y hallazgos. México: COLMEX; 1998. p. 163-192.

Figueroa JG. Fecundidad, anticoncepción y derechos reproductivos. En: García B, coordinadora. Mujer, género y población en México. México: El Colegio de México, Sociedad Mexicana de Demografía; 1999. p. 61-102.
Lerner S. Hacia un enfoque demoantropológico de la nupcialidad y su relación con nuevas expectativas de procreación, reflexiones a partir de un estudio realizado en la zona de influencia del ingenio de Zacatepec, Morelos. Estudios Demográficos y Urbanos.1997;12(5):71-103.

Lerner S. Contextos, instituciones y actores sociales: hacia un enfoque múltiple de las relaciones entre condiciones de vida y comportamiento reproductivo. México: IISUNAM-CICRED; 1998. p.1-34.

Lerner S. Constitución de la descendencia y proceso de integración de las mujeres rurales al sistema biomédico. Estudios Demográficos y Urbanos. 2000;15(2):1-51.

Menéndez EL. Poder estratificación y salud. Análisis de las condiciones sociales y económicas de la enfermedad en Yucatán. México: Ediciones de la Casa Chata; 1981.

Menéndez EL. Hacia una práctica médica alternativa. Cuadernos de la Casa Chata. 1984; 86.

Menéndez EL. Familia, participación social y proceso salud/enfermedad/atención. Acotaciones desde las perspectivas de la antropología médica. En: Mercado FJ, et al coordinadores. Familia, Salud y Sociedad. Experiencias de investigación en México. México: Universidad de Guadalajara, CIESAS, INSP, COLSON; 1993. p. 130-162.

Mummert G. Juntos o desapartados. Migración trasnacional y la fundación del hogar. En: Fronteras Fragmentadas. México: El Colegio de Michoacán, CIDEM; 2000. p. 123-132.

Recibido el 18 de mayo de 2005

Versión final presentada el 29 de junio de 2005

Aprobado el 12 de julio de 2005 